\title{
Microstructural Investigation of D2 Tool Steel during Rapid Solidification
}

\author{
Pooya Delshad Khatibi ${ }^{1}$, A.B. Phillion ${ }^{2}$, H. Henein ${ }^{1}$ \\ ${ }^{1}$ Department of Chemical and Materials Engineering \\ University of Alberta \\ Edmonton, AB T6G 2G6 Canada \\ ${ }^{2}$ School of Engineering \\ University of British Columbia, Okanagan campus \\ Kelowna, BC V1V 1V7 Canada
}

\begin{abstract}
Rapid solidification yields significant enhancement in mechanical properties through reduced microsegregation and the formation of metastable phases. Impulse Atomization (IA) in helium and nitrogen and Water Atomization (WA) have been utilized to produce powders of D2 tool steel of different sizes from 90-1000 $\mu \mathrm{m}$. SEM analysis was carried out to characterize the effect of particle size and cooling gas on the microstructure. It was determined that higher cooling rates result in smaller 2 and a lower percentage of eutectic. SEM image analysis along with coarsening model were used to predict eutectic and primary phase undercooling of different particles. Small particles exhibited a higher amount of undercooling (both primary phase and eutectic undercooling). The particles exposed to a He atmosphere during atomization had a larger amount of eutectic undercooling whereas the nitrogen-cooled samples had larger dendrite spacing. The fraction of primary phase that solidified during the recalescence was then calculated based on the amount of primary phase undercooling under adiabatic conditions. In smaller particles, it was found that there was a larger amount of primary phase solidified during recalescence due to a higher amount of primary undercooling. Based on primary phase undercooling values, critical nuclei radius of austenite and assuming homogenous nucleation the number of austenite unit cells in the stable nucleus was calculated.
\end{abstract}

\section{1- Introduction}

D2 tool steels are widely used in industry owing to a combination of good wear and abrasion properties [1]. The D2 tool steel contains a high volume fraction of carbides that precipitate during the eutectic transformation. The spacing and size of these particles is key for mechanical properties as smaller particles that are closely spaced will result in improved wear resistance [2]. Carbide spacing is mainly controlled by solidification kinetics, and specifically, the secondary dendrite arm spacing of the primary (Fe-rich) phase. The use of a conventional casting process to create components will result in a large secondary dendritearm spacing and thus coarse carbides, while rapid solidification will refine the microstructure to ensure an even distribution of carbides and thus improve strength [3].

It is well known that $\lambda_{2}$ is strongly influenced by cooling rate, as shown in Eq. 1 below [4], where $\lambda_{2}$ is the secondary dendrite arm spacing, $\frac{\Delta T}{t}$ is the cooling rate composed of a temperature range $\Delta T$ and a solidification time $t_{\mathrm{SL}}$, and $B$ and $n$ are experimentally-determined constants with units of $\mu \mathrm{m}\left({ }^{\circ} \mathrm{C} / \mathrm{s}\right)^{\mathrm{n}}$ and dimensionless, respectively.

$$
\lambda_{2}=B\left(\frac{\Delta T}{t_{\mathrm{SL}}}\right)^{-n}
$$


In addition to the cooling rate, undercooling of the liquid prior to grain nucleation has a significant effect on the final microstructure of metallic alloys. For example, Behulova et al. showed that in metal powder formed by rapid solidification, a variation of morphological features correlated with a variation of particle sizes [5]. The importance of eutectic undercooling in modifying the final phase fractions was highlighted in work by Prasad et al. [6]. These authors demonstrated through experimentation and simulation that it was necessary to incorporate the eutectic undercooling in order to accurately predict the eutectic percent. Most recently, Luan et al. [2] reported finding finer and more uniformly dispersed eutectic carbides as a result of higher eutectic undercooling. Finally, at large undercoolings greater than a critical value $\left(\Delta \mathrm{T}_{\text {hyp }}\right)$, the melt will solidify with almost no partitioning of the solute phase, creating a highly supersaturated solid solution [7].

Crystallization of an undercooled melt occurs in two steps: (1) phase nucleation and (2) growth of the solid phase. In rapid solidification processes, undercooling plays a large role in phase nucleation. As shown in the classical theory of homogeneous nucleation $[9,10]$, for a given undercooling a solid nucleus must have a size exceeding a critical radius $\mathrm{r}^{*}$ in order to grow, as shown in Eq. 3, below, where $T_{\mathrm{m}}$ is the equilibrium melting point of the material, $\gamma_{\mathrm{SL}}$ is the surface energy of the solid in contact with the liquid phase and $\Delta H$ is the latent heat of solidification.

$$
r^{*}=\frac{2 \gamma_{S L} T_{m}}{\Delta H \Delta T_{p}}
$$

If the nucleus is smaller than $r^{*}$, it is energetically favorable for the nucleus to melt and will do so. Typically, $r \geq r^{*}$ in order for the nucleus to grow. When nucleation is heterogeneous, $r^{*}$ is the effective radius of the nucleus. The corresponding critical free energy of nucleation $\left(\Delta \mathrm{G}^{*}\right)$ is thus given by Equation 4.

$$
\Delta G^{*}=\frac{2 \gamma_{S L}^{3} T_{m}^{2}}{3 \Delta H^{2} \Delta T_{p}^{2}}
$$

As can be inferred from Eqs. 3 and 4, the critical radius decreases with increasing undercooling, while the driving force for nucleation increases with increasing undercooling. As a result, the smaller nuclei will not only remain in the liquid but will also grow. For the D2 tool steel, this will lead to finer microstructure and smaller carbide precipitates in tool steels.

The release of latent heat associated with growth also plays a large role in microstructure formation due to potential for large undercoolings, and the resulting thermal recalescence [8] once the solid nucleates. It has been noted that the amount of supersaturated solid solution and the formation of other metastable phases in the solid is mostly affected by the fraction of solid that forms during recalescence, $f_{R}$ [7]. Assuming that solidification during recalescence occurs under near-adiabatic conditions, the volume fraction solidifying during the recalescence, $f_{\mathrm{R}}$, can be calculated as follows [7],

$$
f_{\mathrm{R}}=\frac{\Delta T_{p}}{\Delta T_{\mathrm{hyp}}}
$$

where $\Delta T_{\mathrm{p}}$ is the primary phase undercooling, $\Delta T_{\text {hyp }}=\frac{\Delta \mathrm{H}_{\mathrm{f}}}{\mathrm{C}_{\mathrm{p}}^{\mathrm{l}}}$ is the hypercooling limit, $\Delta \mathrm{H}_{\mathrm{f}}$ is the volumetric latent heat of fusion and $C_{p}^{l}$ is the specific heat capacity of the liquid phase. Eq. 2 is a consequence of the fact that the heat released as part of near-adiabatic solidification during recalescence must be absorbed by the surrounding liquid without the temperature exceeding the liquidus. After recalescence, the remaining melt solidifies under Scheil-Gulliver conditions until the solidus or eutectic temperature is reached. The hypercooling limit can be determined if data of $C_{p}^{l}$ and $\Delta H_{f}$ are available, or by measuring the length of the 
post-recalescence plateau, $\mathrm{L}_{\mathrm{P}}$, as a function of undercooling and extrapolating the resulting correction $\mathrm{L}_{\mathrm{P}}(\Delta \mathrm{T})$ to $\mathrm{L}_{\mathrm{P}}=0[7]$.

In the past few years, various rapid solidification techniques such as gas atomization [5,11], electromagnetic levitation [12,13] and laser melting [14] have been used to study the microstructure and carbide formation in ferrous alloys since these techniques allow for experimentation with a wide variation in cooling rate and casting size. The results have revealed grain refined microstructures and relatively small carbide phases created by high amount of undercooling and cooling rate. However, a systematic experimental work on the rapid solidification of D2 tool steels is still lacking. In this paper, the effect of cooling rate and undercooling on microstructure evolution in D2 tool steel is investigated using the rapid solidification techniques of Impulse Atomization and Water Atomization. Focus is placed on measuring the volume fractions and morphology of the primary phase and eutectic in order to experimentally determine the link between carbide spacing, undercooling temperatures for nucleation, and cooling rate. This data is needed in order to assist in the development of new casting methods, such as spray forming, for tool steel applications. In a subsequent study, knowledge of the degree to which the matrix phase is supersaturated as a function of undercooling and cooling rate will be used to investigate carbide precipitation in rapidly solidified D2 tool steel as a result of the post solidification heat treatment.

\section{2- Experimental}

The D2 tool steel is a high carbon, high chromium ferrous alloy with $1.55 \%$ carbon, $11.8 \%$ chromium, 0.40\% manganese, $0.80 \%$ molybdenum, $0.80 \%$ vanadium and $\mathrm{Fe}$ in balance (all in wt.\%). The corresponding phase diagram is shown in Figure 1, with a line highlighting the carbon content of the given D2 tool steel. This pseudo-binary phase diagram was calculated using the ThermoCalc software v. 5.0.4.75 and the TCFE6 data bank v. 6.0.

In order to investigate solidification microstructure under rapid cooling rates, two experimental techniques, Impulse Atomization (IA) and Water Atomization (WA) have been utilized. In the IA method [15], the D2 tool steel powder was obtained as follows. First, a bulk alloy was melted and held in an alumina crucible for about 30 minutes at $1600{ }^{\circ} \mathrm{C}$. Then, the liquid was pushed through orifices at the bottom of the crucible to create droplets via atomization. The falling liquid droplets were then cooled in both helium and nitrogen atmospheres having a maximum oxygen content of $8 \mathrm{ppm}$, and thus solidified before reaching the bottom of the atomization chamber. Cooling rate is both a function of droplet size, and the gas used to atomize the molten metal. For the WA method [16,17] the molten metal exits the furnace as a free-falling stream and is then broken up into droplets using high-velocity water jets. The D2 tool steel powder from IA was generated using an apparatus available at the University of Alberta, while the WA powder was provided by the Hoeganaes Corporation. Table 1 shows the IA and WA atomization run conditions as well as the geometric standard deviation of mass distribution ( $\sigma$ ) and median diameter (D50) of the particles produced under each testing condition. As can be seen, WA produces smaller particles as compared to IA. Also, as noted elsewhere [15][18], IA powders have perfectly spherical shapes whereas WA powder is irregular.

Subsequent to the atomization processes, the IA D2 tool steel powder was washed using toluene and methanol, and then sieved into different size ranges based on MPIF Standard 05 [19]. Size ranges of 300$355 \mu \mathrm{m}, 600-710 \mu \mathrm{m}$ and $1000-1400 \mu \mathrm{m}$ were chosen from the IA powder and size ranges of $90-110 \mu \mathrm{m}$, 300-355 $\mu \mathrm{m}$ and 600-710 $\mu \mathrm{m}$ were chosen from the WA powder for further analysis. For each of the different powder size fractions, specimens were mounted in epoxy resin, ground, polished, and then carbon coated in preparation for metallography. Scanning electron microscopy (SEM) with Energy-dispersive Xray spectroscopy (EDX) was performed using a Hitachi S-2700 Scanning Electron Microscope equipped with a PGT (Princeton Gamma-Tech) PRISM IG (Intrinsic Germanium) detector for Energy Dispersive XRay Analysis in order to measure both $\lambda_{2}$ and the area fraction of eutectic. For $\lambda_{2}, 60$ measurements per specimen were performed using the Image Tool software in order to accurately determine this parameter. 
For the measurement of the eutectic fraction, an overlaid grid method was utilized [20] whereby a grid pattern of $2 \mu \mathrm{m}$ spacing was superimposed onto the SEM images. The error bars reported in the results represents the standard deviation from the mean based on the length and area measurements. Additionally, quantitative phase identification was carried out through X-ray diffraction using Co-K $\alpha$ radiation in a Rigaku Denki Rotaflex RU-200B X-ray system.

\section{3- Results}

Below we provide a concise description of the D2 tool steel microstructure morphology that is found in powders atomized by Impulse Atomization and Water Atomization. First, the morphology of different particles sizes produced from IA (atomized in $\mathrm{He}$ and $\mathrm{N}_{2}$ ) and WA will be described. Then, quantification of some important microstructural and solidification parameters will be discussed. Finally, the effect of solidification parameters including cooling rate and undercooling on microstructural features will be investigated. As it was not possible to measure directly the temperature of the droplets during atomization, a methodology for estimating the amount of undercooling prior to nucleation of the primary phase and eutectic based on metallographic analysis will be presented [21].

\subsection{Qualitative Description of the Microstructure}

The images shown in Figure 2 are SEM micrographs of three D2 tool steel particles produced by IA: (a) a $325 \mu \mathrm{m}$ particle cooled in helium, (b) a $325 \mu \mathrm{m}$ particle cooled in nitrogen, and (c) a $655 \mu \mathrm{m}$ particle cooled

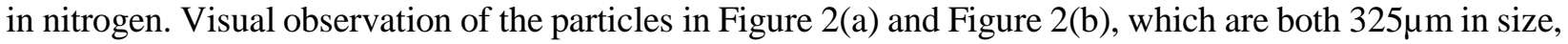
shows that the microstructure is finer for particles solidified in helium (Figure 2(a)) versus those solidified in nitrogen (Figure 2(b)). Since the thermal conductivity of helium is significantly higher than that of nitrogen [22], droplets in helium solidify faster, resulting in a finer microstructure. Light and dark gray phases, as well as some solidification porosity can also be seen in both images. In comparing Figure 2(b) with Figure 2(c), it can also be seen that changes in the particle size also affect the scale of the microstructure since the larger particle has a comparatively coarse microstructure. This is due to the fact that heat transfer and hence cooling rate is higher in smaller particles due to their larger surface-to-volume ratio. The same effect was seen on the WA particles.

Figure 3 shows XRD results for IA particles of $600-710 \mu \mathrm{m}$ in diameter cooled using both helium and nitrogen, as well as comparatively-sized WA particles. It can be seen from the figure that the rapid solidification of D2 steel during atomization results in the formation of supersaturated metastable retainedaustenite as well as the complete suppression of ferrite and martensite. The austenite in the rapidly solidified D2 steel particles was so stable that the retained austenite did not convert to martensite even after a quench in liquid nitrogen. The reason is likely the lowering of the martensite start temperature caused by high supersaturation of austenite. Bhargava et al. [23] reported similar microstructure for rapidly solidified D2 steel using the melt spun method, and showed that the lattice parameter of austenite in melt-spun D2 steel was approximately $1.5 \%$ larger than that for $\gamma$-Fe, indicating substantial dissolution of carbon and chromium in the austenite. In contrast, the formation of a small amount of martensite has been reported by Grgac et al. [12] for rapidly solidified $\mathrm{Cr}-\mathrm{Mo}-\mathrm{V}$ tool steel. In the work of Grgac, ledburite-type tool steel was electromagnetically levitated in order to produce material with a range of cooling rates and undercoolings.

\subsection{Quantitative Analysis}

EDX analysis results from the different grey levels shown in Figure 2 are given in Table 2. As can be seen, the dark grey material contains higher levels of alloying elements ( $\mathrm{Cr}, \mathrm{Mn}, \mathrm{Mo}$, and $\mathrm{V}$ ), indicating that these were rejected during the solidification process. Based on this compositional analysis and the phases identified from $\mathrm{XRD}$, the light gray phase is primary metastable retained austenite, while the dark phase is the eutectic material: austenite and a $\mathrm{M}_{7} \mathrm{C}_{3}$ carbide. 
The effect of cooling rate on solidification microstructure was quantified based on $\lambda_{2}$. Table 3 lists the $\lambda_{2}$ (measured using Image Tool software) of the WA and IA particles as a function of particle size. The IA particles are also sorted as a function of cooling gas. The results shown in Table 3 provide a quantitative assessment of the observations made in Figure 2 - by decreasing particle size, and changing the cooling gas from nitrogen to helium, $\lambda_{2}$ decreases. Similar effect have been previously reported in the literature for $\mathrm{Al}$ alloy and D2 systems [24,25, reference your paper].

High magnification SEM images of the eutectic material in IA particles, shown in Figure 4, indicate that the eutectic structure of particles atomized in helium (Figure 4(a)) is much finer as compared to the particles atomized in nitrogen (Figure 4(b)) for the same particle size. Concurrently, the intercellular spacing is higher for the case of solidification in nitrogen $(0.11 \pm 0.04 \mu \mathrm{m}$, Figure $4(\mathrm{~b}))$ as compared to that in helium $(0.22 \pm 0.05 \mu \mathrm{m}$, Figure 4(a)). Based on work by Fischmeister et al. [26], the thickness of eutectic lamellae is proportional to $(\mathrm{dT} / \mathrm{dt})^{-1 / 4}$, where $\mathrm{dT} / \mathrm{dt}$ is the eutectic cooling rate. Thus, the measurements of the intercellular spacing suggest that the eutectic cooling rate for solidification in helium is approximately 16 times higher than that of nitrogen for the $1200 \mu \mathrm{m}$-sized particle. A high magnification SEM image of the eutectic material in a $655 \mu \mathrm{m}$ WA particle is also provided in Figure 4, for comparison purposes. In this particle, the eutectic lamellar spacing is about $0.10 \pm 0.03 \mu \mathrm{m}$. Since the intercellular spacings calculated for Figure 4(a) and Figure 4(c) are very similar, it can be concluded that the cooling rates during solidification in WA and IA with helium are almost the same for the same sized powder.

Figure 5 shows the effect of cooling gas and particle size on the amount of eutectic in WA and IA particles based on image analysis. First, it can be seen that the eutectic area fraction is smaller for the particles that were more rapidly solidified. Second, for the IA particles, the error bars increase with increasing particle size. This indicates that, similar to Al-Cu and Al-Fe systems [27,28], the D2 tool steel particles are not homogeneous at the scale of the microstructure.

The equilibrium and Scheil eutectic fractions are also provided on Figure 5, for comparison purposes. As can be seen, the measured values of eutectic area fraction for D2 tool steel are considerably less than what is predicted by the two limiting theoretical cases. Previous atomization studies, with $\mathrm{Al}-\mathrm{Fe}$ and $\mathrm{Al}-\mathrm{Cu}$, have shown that eutectic undercooling is responsible for this reduction in the fraction eutectic [27,28]. Kurz and Trivedi have shown that by increasing the solidification rate (which results in the higher growth velocity), the equilibrium phase diagram is changed so that there are reduced amounts of eutectic [29]. The same trend has been shown for rapidly solidified Al-Cu and Al-Si alloys by Sarreal and Abbaschian [30]. These authors attributed the lower amount of eutectic to both dendrite tip undercooling as well as eutectic undercooling. Formation of the eutectic can even be suppressed completely, due to formation of a metastable supersaturated solid solution [31]. This is attributed to the features of rapid solidification, as the interface velocity is higher than the solute diffusion speed in bulk phases.

\subsection{Solidification kinetics}

The measured $\lambda_{2}$ values shown in Table 3, in combination with the eutectic fraction measurements shown in Figure 5 can be used to provide new insight into the solidification kinetics of the D2 tool steel. Four insights are presented below.

Eutectic Undercooling: Based on the results shown in Figure 5, it would appear that the atomization process produces material with a wide range of eutectic fraction. For the IA process, the eutectic fraction varies from $8-20 \%$ as a function of particle size. In contrast, the equilibrium (lever-rule) eutectic content of a D2 tool steel with $1.55 \mathrm{wt} \% \mathrm{C}$, based on the phase diagram shown in Figure 1, is approximately $22 \%$ with the transformation occurring at $1270^{\circ} \mathrm{C}$. Assuming equilibrium solidification, it is possible to estimate the required undercooling prior to nucleation of the eutectic by comparing the measured values to the eutectic fractions predicted via metastable extensions of the liquidus and solidus lines below the equilibrium eutectic 
temperature. The results are provided in Figure 6. As can be seen, larger undercoolings are found to occur when the eutectic fraction is small. As the eutectic fraction is inversely related to particle size (Figure 5), it can be postulated that the fine eutectic lamellae spacing observed in Figure 4(c) and other small particles is directly related to undercooling temperature.

Solidification time of the Primary phase: The secondary dendrite spacing, $\lambda_{2}$, can be expressed as a function of the coarsening kinetics and is proportional to the cube root of time,

$$
\begin{aligned}
& \lambda_{2}=5.5\left(M t_{\mathrm{SL}}\right)^{\frac{1}{3}} \\
& M=\frac{-\Gamma D \ln \left(\frac{C_{l}^{m}}{C_{0}}\right)}{m(1-k)\left(C_{l}^{m}-C_{0}\right)}
\end{aligned}
$$

where $\Gamma$ is the Gibbs-Thompson coefficient ( $\Gamma=10^{-7} \mathrm{mK}$ [32]), $D$ is the diffusion coefficient of solute in the liquid $\left(D=10^{-9} \mathrm{~m}^{2} \mathrm{~s}^{-1}[33]\right), m$ is the slope of the liquids line, $C_{\mathrm{l}}^{\mathrm{m}}$ is the composition of the last liquid to solidify, $C_{0}$ is the overall composition, $t_{\mathrm{SL}}$ is the solidification time of the primary phase, and the units of $\lambda_{2}$

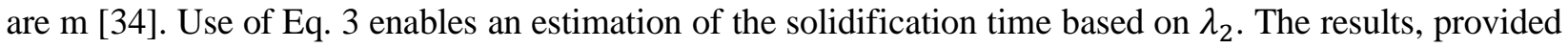
in Table 4, indicate that there is considerable range in $t_{\mathrm{SL}}$ as a function of the atomization conditions and particle size; obviously smaller particles solidify faster.

Primary Phase Solidification Interval: Equating Eq. 3 (which relates $\lambda_{2}$ with solute partitioning) with Eq. 1 (which relates $\lambda_{2}$ to cooling rate), and assuming $n=\frac{1}{3}$ leads to the expression given below,

$$
\Delta T=\left(\frac{B \times 10^{-6}}{5.5}\right)^{3} \times \frac{1}{M}
$$

where $B=42.1 \mu \mathrm{m}\left({ }^{\circ} \mathrm{C} / \mathrm{s}\right)^{\mathrm{n}}$ [35]. This expression enables for calculation of the solidification interval of the primary phase since the temperature range $\Delta T$ represents the range over which the secondary dendrite arms coarsen, i.e. $\Delta T=T_{\text {primary }}^{n u c}-T_{\text {eutectic }}^{n u c}$. Although the assumption $n=\frac{1}{3}$ is significant, it is consistent with experimentally-determined values of $n$ for other steel alloys during rapid solidification [35,your previous paper on D2]. The resulting values of $\Delta T$ for the various atomized particles are provided in Table $4 . \Delta T$ is found to vary with particle size and atomization method since $C_{\mathrm{l}}^{\mathrm{m}}$ term in Eq. 4 is not taken to be the equilibrium eutectic composition but rather the values taken from the metastable liquidus line for D2 tool steel as calculated based on the eutectic area fraction measurements and Figure 5.

Primary Phase Undercooling, $\Delta \mathrm{T}_{\mathrm{p}}$ : With $\Delta \mathrm{T}$, and the eutectic undercooling temperatures derived from the eutectic fractions, one can calculate the nucleation temperature of the primary phase and the corresponding undercooling as compared to the equilibrium phase diagram. It can be seen from Figure 7 that for rapid solidification, larger primary phase undercooling results in a smaller eutectic fraction. Figure 8 shows a direct relationship between particle size and primary phase undercooling. As can be seen, the primary phase undercooling only slightly decreases with an increase in the particle size to $655 \mu \mathrm{m}$. But, a further increase in particle size to $1000 \mu \mathrm{m}$ results in a significant decrease in undercooling for the case with a nitrogen atmosphere. The calculated values of $\Delta \mathrm{T}$ and $\mathrm{t}_{\mathrm{SL}}$ from Table 4 for different $\mathrm{D} 2$ tool steel particle sizes during IA in helium and nitrogen, and WA, can be used to directly determine the average cooling rate of the primary phase during atomization. These average cooling rates are provided in Figure 9 as a function of eutectic fraction. As is shown, the eutectic fraction is inversely proportional to the primary phase cooling rate. 
The methodology outlined above for calculating the solidification interval and the undercooling of the primary phases does not take into account the dendrite tip kinetics, and is therefore a significant approximation. But, as shown in Figures 7 and 8, considerable variation in undercooling is predicted to occur as a function of particle size and cooling gas, matching our understanding of the atomization process. In a companion work [21] on IA rapidly solidified Al-10wt.\%Cu droplets, primary phase undercooling data calculated using the coarsening model approach outlined in Eq. 5 was compared to results obtained from comprehensive study of eutectic undercooling that combined neutron diffraction analysis of undercooling temperature, and a microsegregation model of solidification [36]. This comparison found the coarsening approximation to be within 10-15\% of the work by Prasad et al. [6] thus validating the use of this methodology to qualitatively characterize primary phase undercooling and nucleation during solidification.

Fraction Solidified during Recalescence, $f_{\mathrm{R}}$ : The fraction solidified during recalescence can be calculated using Eq. 2, and the primary phase undercoolings provided in Figure $8^{1}$. The calculated $f_{\mathrm{R}}$ values for the IA droplets in He and N2 as well as WA droplets are shown in Table 4. Considering these results, along with the primary phase undercooling presented in Figure 7, it can be seen that $f_{\mathrm{R}}$ increases with increasing primary phase undercooling. This result is consistent with the work of Prasad et al [38], who showed using a combination of experimental and modeling activities that an increase in the primary phase undercooling for $\mathrm{Al}-\mathrm{Cu}$ alloys results in an increase in the fraction of eutectic that forms during recalescence.

\section{4- Discussion}

The microstructure morphology and solidification kinetics during IA and WA presented in Section 3 can provide new insight into the rapid solidification of D2 tool steel, and its effect on carbide formation during subsequent heat treatment. As shown in Figure 8, larger undercoolings are required in the small particles prior to primary phase nucleation, which results in the formation of more austenite during the recalescence event. Since the amount of supersaturated solid solution is affected by $f_{\mathrm{R}}$ [7], it can be hypothesized that there will be different levels of supersaturation according to the degree of undercooling achieved in different particles; smaller particles will be have higher levels of supersaturation in alloying elements as compared to the larger ones. As the degree of supersaturation provides the driving force for precipitation of secondary phases during heat treatment, smaller particles will thus precipitate carbides on a finer scale, providing enhanced mechanical properties [39]. At the same time, there is a limit to the degree of undercooling, and hence carbide spacing, that can be achieved with rapid solidification. Although the hypercooling limit for the D2 tool steel under adiabatic solidification conditions is about $264^{\circ} \mathrm{C}$, the maximum value found achieved in the IA experiments is about $140^{\circ} \mathrm{C}$. At the smaller particle sizes, the primary phase undercooling is not varying all that much as so it would appear that is an effective hypercooling limit.

The use of Eq. 2 to calculate the formation of the solid phase during recalescence is based on the assumption of adiabatic solidification. However, the variation in $\lambda_{2}$ shown in Table 3 and in eutectic fraction shown in Figure 5 would indicate that microstructure is indeed affected by the choice of cooling gas $\left(\mathrm{He}, \mathrm{N}_{2}\right)$. Therefore, solidification of these particles cannot be considered as completely adiabatic. As shown in Figure 8 , the largest particles appear to be largely affected by the choice of cooling gas. In the smaller particles, only a slight increase in undercooling is obtained when cooling with helium as compared to nitrogen. Due to the small volume of the smaller particles, and therefore less latent heat of fusion, most of the heat generated during solidification is accommodated by the liquid, which minimizes the effect of the cooling gas. In the larger particles, however, the abundance of active nucleation sites, can be overcome by the increased cooling power of helium, causing droplets to begin solidification at larger undercoolings. At this size, solidification is controlled mainly by external heat extraction, as found previously in [40].

\footnotetext{
1 The hypercooling limit of $264^{\circ} \mathrm{C}$ for $\mathrm{D} 2$ tool steel was calculated from $\Delta \mathrm{H}_{\mathrm{f}}$ and $\mathrm{C}_{\mathrm{p}}^{\mathrm{l}}$ material property values taken from ThermoCalc $\left(8.70 \times 10^{8}\right.$ $\mathrm{Jm}^{-3}, 3.30 \times 10^{6} \mathrm{JK}^{-1} \mathrm{~m}^{-3}$ )
} 
As shown by Eq. 3, the critical radius required for homogeneous grain nucleation will decrease with increasing undercooling. Although homogeneous nucleation is unlikely to be occurring during atomization, this classical theory provides a good comparative assessment of undercooling effects. Using information provided by Mizukami et al. [37] for $\gamma_{\mathrm{SL}}$, the critical radius for austenite nucleation in D2 tool steel can be calculated. Figure 10 shows the critical radius of the austenite nuclei as a function of different primary phase undercooling during atomization. The smallest radii belong to the WA droplets, which had the highest primary phase undercooling, while the largest critical radius belongs to the IA- $\mathrm{N}_{2}$ droplets. Assuming $\mathrm{a}_{\text {austenite }}=0.3618 \mathrm{~nm}$ (Powder Diffraction File\#52-0512), the number of austenite unit cells that must join to form the stable nuclei can be calculated. Figure 11 shows that in the droplets with the small amount of primary undercooling, larger number of unit cells need to be joined in order to form the stable nuclei. This reduces the chance of successful grain nucleation during solidification and therefore a coarser microstructure is formed. As shown in the SEM micrographs, droplets with lower primary phase undercooling have coarser microstructure compared to the ones that have higher primary phase undercooling. Therefore, by prediction of primary phase undercooling, one can have a good estimation about the size of nuclei which can help to predict size of the final microstructure of solidified droplets.

\section{5- Conclusion}

In this study, the microstructure obtained during Impulse and Water atomization has been qualitatively and quantitatively compared. The results have provided new insight into solidification kinetics:

(1) A finer microstructure, smaller SDAS and finer eutectic lamellae is obtained when helium is used as a cooling gas during IA as compared to using nitrogen .

(2) A finer microstructure, smaller SDAS and thinner eutectic carbides lamellae was observed in the smaller particles due to higher cooling rates.

(3) There is a higher amount of eutectic and primary phase undercooling in particles with higher cooling rate.

(4) Smaller particles require a larger undercooling for primary phase and eutectic nucleation.

(5) Solidification of small particles can be considered as "near adiabatic", since primary phase undercooling is not largely affected by the cooling gas, compared to the larger particles.

\section{7- References}

[1] G. Roberts, G. Krauss, R. Kennedy, Tool Steels, 5th ed., ASM International, Ohio, 1998.

[2] Y. Luan, N. Song, Y. Bai, X. Kang, D. Li, Effect of solidification rate on the morphology and distribution of eutectic carbides in centrifugal casting high-speed steel rolls, Journal of Materials Processing Technology. 210 (2010) 536-541.

[3] Y. Dai, M. Yang, C. Song, Q. Han, Q. Zhai, Solidification structure of C2.08Cr25.43Si1.19Mn0.43Fe70.87 powders fabricated by high pressure gas atomization, Materials Characterization. 61 (2010) 116-122.

[4] G. Helmersson, K. Burgdorf, Effects of process parameters on microstructure of gas atomized powder, Scandinavian Journal of Metallurgy. 25 (1996) 51-58.

[5] M. Behulova, R. Moravcik, M. Kusy, L. Caplovic, P. Grgac, L. Stancek, Influence of atomisation on solidification microstructures in the rapidly solidified powder of the $\mathrm{Cr}-\mathrm{Mo}-\mathrm{V}$ tool steel, Materials Science and Engineering: A. 304-306 (2001) 540-543. 
[6] A. Prasad, S. Mosbah, H. Henein, C.-A. Gandin, A Solidification Model for Atomization, ISIJ International. 49 (2009) 992-999.

[7] D. Herlach, D. Holland-Moritz, P. Galenko, Metastable Solids from Undercooled Melts, Pergamon, 2007.

[8] A. Ilbagi, P. Delshad Khatibi, H. Henein, C.-A. Gandin, D. Herlach, Quantification of Primary Phase Undercooling of Rapidly Solidified Droplets with 3D Microtomography, in: International Conference on 3D Materials Science, TMS, Seven Springs, Pennsylvania, 2012.

[9] D.A. Porter, K.E. Easterling, Phase Transformations in Metals and Alloys, 2nd Editio, Chapman \& Hall, London, 1992.

[10] M.C. Flemings, Solidification Processing, 1st Editio, Mcgraw-Hill Publication, 1974.

[11] N.H. Pryds, A.S. Pedersen, Rapid Solidification of Martensitic Stainless Steel Atomized Droplets, Metallurgical and Materials Transactions A. 33 (2002) 3755-3761.

[12] P. Grgac, M. Liptak, M. Behulova, L. Caplovic, H.-G. Lindenkreuz, W. Löser, Influence of melt undercooling on the microstructure of levitated $\mathrm{Cr}-\mathrm{Mo}-\mathrm{V}$ tool steel, Materials Science and Engineering: A. 449-451 (2007) 658-661.

[13] M. Behúlová, M. Lipták, P. Grgač, W. Löser, H.-G. Lindenkreuz, Comparison of microstructures developed during solidification of undercooled tool steel in levitation and on a substrate, Journal of Physics: Conference Series. 144 (2009) 012099.

[14] K.Y. Benyounis, O.M. Fakron, J.H. Abboud, Rapid solidification of M2 high-speed steel by laser melting, Materials \& Design. 30 (2009) 674-678.

[15] H. Henein, Single fluid atomization through the application of impulses to a melt, Materials Science and Engineering: A. 326 (2002) 92-100.

[16] M. Covaciu, T. Canta, E. Gordo, Characterization and Sinterability Study of P.M. High-Speed Steel Obtained by Water Atomization, Advanced Materials Research. 23 (2007) 147-150.

[17] Y. Seki, S. Okamoto, H. Takigawa, N. Kawai, Effect of atomization variables on powder characteristics in the high-pressured water atomization process, Metal Powder Report. 45 (1990) $38-40$.

[18] J. Hamill, C. Schade, N. Myers, Water Atomized Fine Powder Technology, Cinnaminson, New Jersey, n.d.

[19] Standard test methods for metal powders and powder metallurgy products, Metal Powder Industries Federation, Princeton, NJ, 1993.

[20] M. Oberholzer, M. Ostreicher, H. Christen, M. Brühlmann, Methods in quantitative image analysis., Histochemistry and Cell Biology. 105 (1996) 333-55. 
[21] A. Bogno, P. Delshad Khatibi, H. Henein, C.-A. Gandin, Quantification of Primary and Eutectic undercoolings of Impulse Atomized Al-Cu droplets, in: Materials Science \& Technology 2013, Montreal, Quebec, Canada, 2013.

[22] W.M. Rohsenow, J.P. Hartnett, Handbook of Heat Transfer, 3rd ed., McGraw-Hill, 1998.

[23] A.K. Bhargava, A.N. Tiwari, Effect of rapid solidification and heat treatment on D2 steel, International Journal of Rapid Solidification. 7 (1992) 51-66.

[24] L. Han, X. Nie, D. Northwood, H. Hu, Effect of Cooling Rates on the Microstructure Evolution and Eutectic Formation of As-cast Mg-Al-Ca Alloys, in: SAE World Congress \& Exhibition, Detroit, 2009.

[25] A. Ilbagi, H. Henein, A.B. Phillion, Phase quantification of impulse atomized A168.5Ni31.5 alloy, Journal of Materials Science. 46 (2010) 6235-6242.

[26] H.F. Fischmeister, R. Riedl, S. Karagöz, Solidification of High-Speed Tool Steels, 20 (1989).

[27] A. Prasad, H. Henein, E. Maire, C. Gandin, Understanding the Rapid Solidification of Al-4.3Cu and Al-17Cu Using X-Ray Tomography, 37 (2006).

[28] H. Henein, V. Buchoud, R. Schmidt, C. Watt, D. Malakov, C. Gandin, et al., Droplet Solidification of Impulse Atomized Al-0.61Fe and Al-1.9Fe, 49 (2010) 275-292.

[29] W. Kurz, R. Trivedi, Eutectic growth under rapid solidification conditions, Metallurgical Transactions A. 22 (1991) 3051-3057.

[30] J.A. Sarreal, G.J. ABbaschian, The effect of solidification rate on microsegregation, Metallurgical Transactions A. 17 (1986) 2063-2073.

[31] N.S. Miroshnichenko, Quenching from the Liquid State (in Russian), Moscow, 1982.

[32] R. Hashimoto, Y. Shibuta, T. Suzuki, Estimation of Solid-liquid Interfacial Energy from GibbsThomson Effect: A Molecular Dynamics Study, ISIJ International. 51 (2011) 1664-1667.

[33] J. Miettinen, Thermodynamic-kinetic simulation of constrained dendrite growth in steels, Metallurgical and Materials Transactions B. 31 (2000) 365-379.

[34] W. Kurz, D.J. Fisher, Fundamentals of Solidification, Enfield Publishing \& Distribution Company, 1998.

[35] M. Boccalini, H. Goldenstein, Solidification of high speed steels, International Materials Reviews. 46 (2001) 92-115.

[36] C.-A. Gandin, S. Mosbah, T. Volkmann, D.M. Herlach, Experimental and numerical modeling of equiaxed solidification in metallic alloys, Acta Materialia. 56 (2008) 3023-3035. 
[37] H. Mizukami, K. Hayashi, M. Numata, A. Yamanaka, Prediction of Solid-liquid Interfacial Energy of Steel during Solidification and Control of Dendrite Arm Spacing, ISIJ International. 52 (2012) 2235-2244.

[38] A. Prasad, H. Henein, E. Maire, C. a. Gandin, X-ray tomography study of atomized Al-Cu droplets, Canadian Metallurgical Quarterly. 43 (2004) 273-282.

[39] P. Delshad Khatibi, D.G. Ivey, H. Henein, Effect of rapid solidification and heat treatment on D2 tool steel, in: TMS Annual Meeting, Orlando, FL, United States, 2012: pp. 505-512.

[40] A.L. Genau, Microstructural development in Al-Si powder during rapid solidification, Iowa State University, 2004.

\section{6- Acknowledgements}

Funding from the Canadian Space Agency and the Natural Sciences and Engineering research Council of Canada is acknowledged. The authors are also grateful to Hoeganaes Corporation and to Chris Schade from Hoeganaes for the supply of WA powder. 
Table 1. IA and WA run conditions and atomized particle size distribution

\begin{tabular}{cccccc}
$\begin{array}{c}\text { Atomization } \\
\text { technique }\end{array}$ & $\begin{array}{c}\text { Atomization } \\
\text { atmosphere }\end{array}$ & $\begin{array}{c}\text { Number of } \\
\text { orifices }\end{array}$ & $\begin{array}{c}\text { Orifice size } \\
(\mu \mathrm{m})\end{array}$ & D50 $(\mu \mathrm{m})$ & $*_{\sigma}$ \\
\hline \multirow{2}{*}{ IA } & $\mathrm{He}$ & 37 & 420 & 670 & 1.16 \\
& $\mathrm{~N}_{2}$ & 37 & 400 & 510 & 1.22 \\
WA & $\mathrm{H}_{2} \mathrm{O}$ & N/A & N/A & 70 & 1.64 \\
\hline
\end{tabular}

$* \sigma=\frac{\mathrm{D} 84}{\mathrm{D} 50}$

Table 2. EDX analysis results from dark and light gray regions in D2 steel (shown in Figure 3) (wt.\%)

\begin{tabular}{llllll}
\hline & Fe & Cr & Mn & Mo & V \\
\hline Light Gray & 89.33 & 9.5 & 0.37 & 0.39 & 0.41 \\
Dark Gray & 74.03 & 21.22 & 1.41 & 1.32 & 2.02 \\
\hline
\end{tabular}

Table 3. Secondary dendrite-arm spacing as a function of particle size and cooling gas

\begin{tabular}{llll}
\hline \multirow{2}{*}{ Particle size range $(\mu \mathrm{m})$} & \multicolumn{2}{l}{ Average $\lambda_{2}(\mu \mathrm{m})$} & \\
\cline { 2 - 4 } & Impulse Atomized in He & Impulse Atomized in N2 & Water Atomized \\
\hline $90-110$ & - & - & $1.02 \pm 0.43$ \\
$300-355$ & $2.41 \pm 0.34$ & $3.84 \pm 0.07$ & $1.87 \pm 0.21$ \\
$600-710$ & $3.98 \pm 0.73$ & $6.03 \pm 1.10$ & $4.13 \pm 0.20$ \\
$1000-1400$ & $5.63 \pm 1.01$ & $7.58 \pm 1.03$ & - \\
\hline
\end{tabular}

Table 4. Solidification kinetics for particles atomized under different conditions

\begin{tabular}{|c|c|c|c|c|c|c|c|c|c|}
\hline Atomization method & $\mathrm{IA}(\mathrm{He})$ & & & IA (N2) & & & WA & & \\
\hline Particle size range $(\mu \mathrm{m})$ & $300-355$ & $600-710$ & $1000-1400$ & $300-355$ & $600-710$ & $1000-1400$ & $90-110$ & $300-355$ & $600-710$ \\
\hline Solidification time (s) & $1.03 \times 10^{-2}$ & $4.63 \times 10^{-2}$ & $1.29 \times 10^{-1}$ & $4.15 \times 10^{-2}$ & $1.59 \times 10^{-1}$ & $3.02 \times 10^{-1}$ & $8.04 \times 10^{-4}$ & $4.86 \times 10^{-3}$ & $5.20 \times 10^{-2}$ \\
\hline $\begin{array}{l}\text { Solidification } \\
\text { temperature range }\left({ }^{\circ} \mathrm{C}\right)\end{array}$ & 55.11 & 54.84 & 53.88 & 54.64 & 54.25 & 51.71 & 56.50 & 55.50 & 55.11 \\
\hline $\mathrm{f}_{\mathrm{R}}(\mathrm{Vol} . \%)$ & $52.8 \pm 0.9$ & $51.7 \pm 0.5$ & $46.9 \pm 1.0$ & $49.9 \pm 0.8$ & $48.4 \pm 1.2$ & $38.7 \pm 2.1$ & $57.6 \pm 0.5$ & $53.4 \pm 0.3$ & $51.8 \pm 0.3$ \\
\hline
\end{tabular}




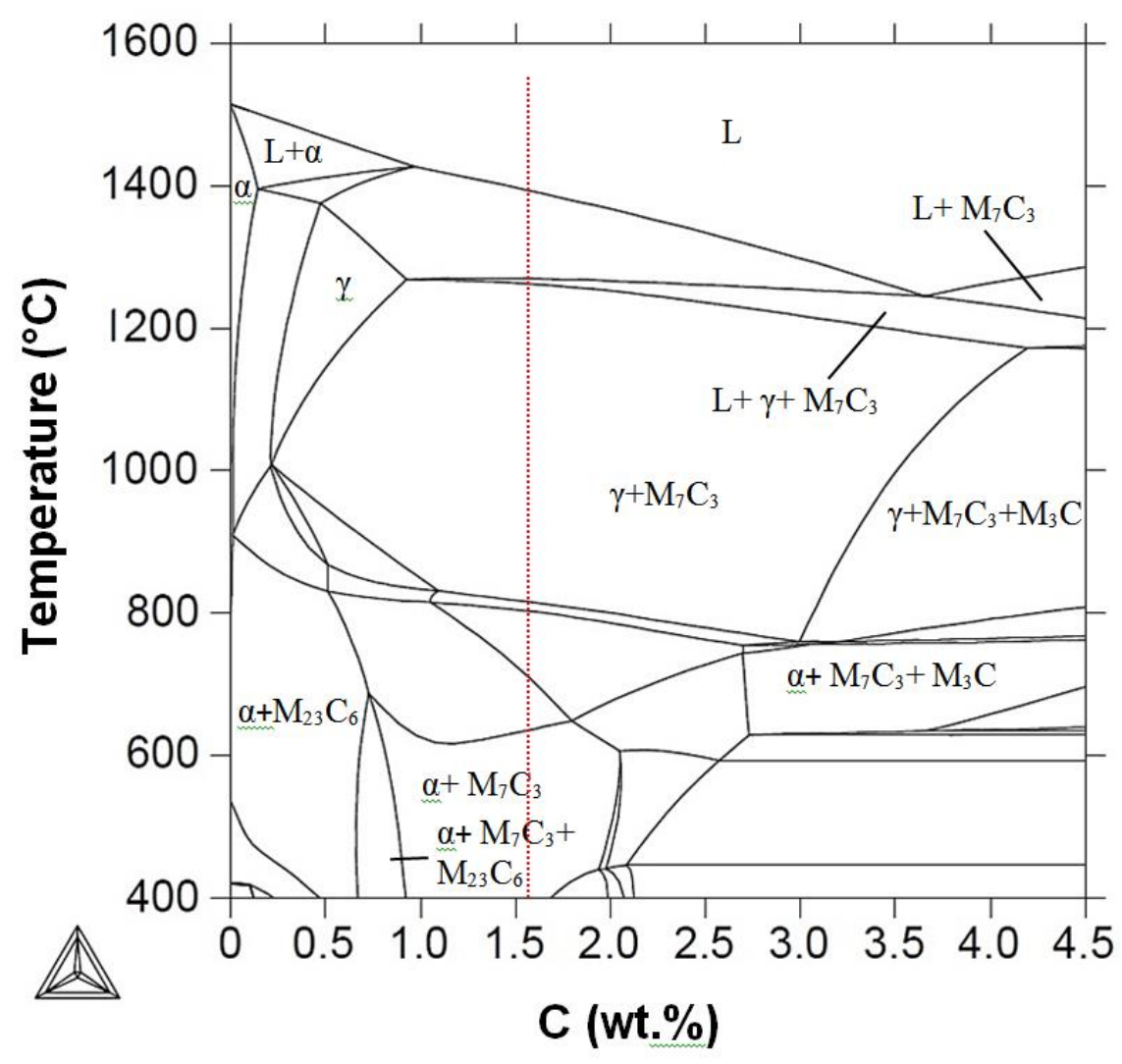

Figure 1. Calculated phase diagram for D2 tool steel from TCFE6 database using ThermoCalc software. 


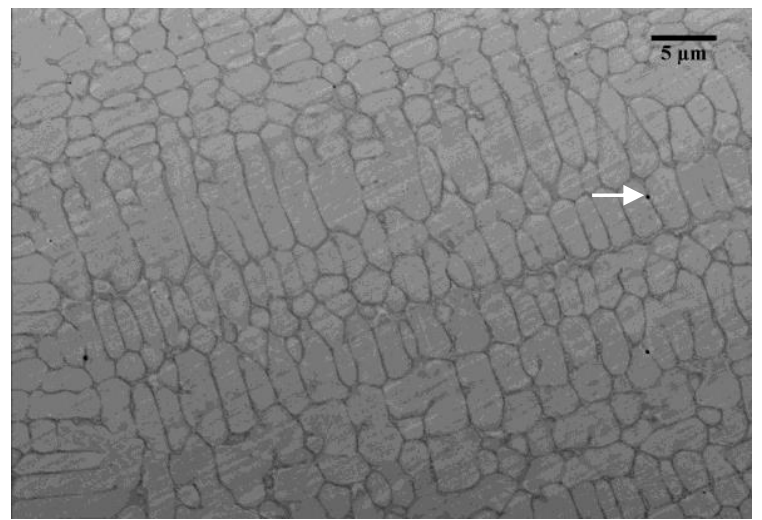

(a)

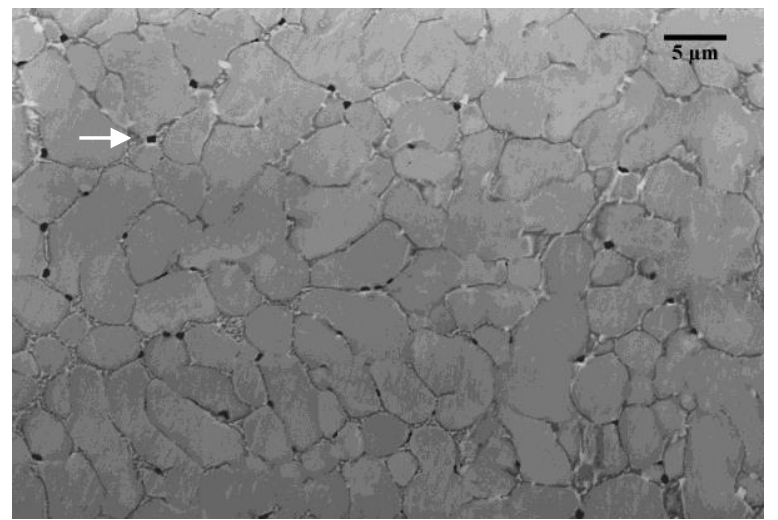

(b)

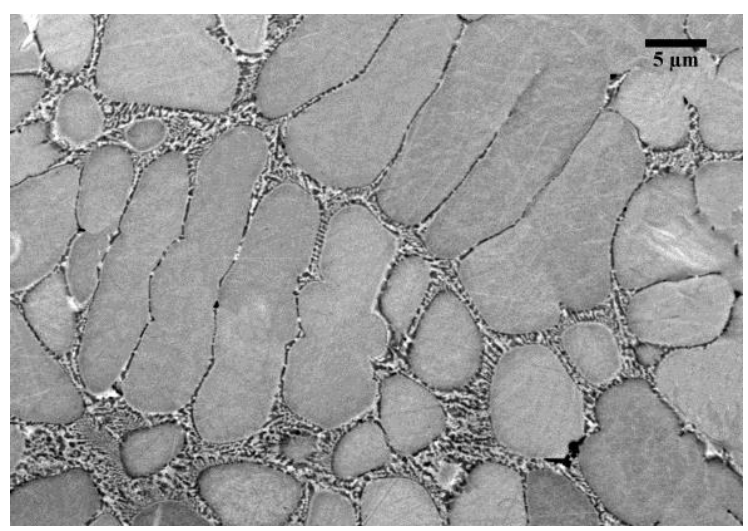

(c)

Figure 2. D2 tool steel particles formed by IA: (a) $325 \mu \mathrm{m}$ particle atomized in helium, (b) $325 \mu \mathrm{m}$ particle atomized in nitrogen and (c) $655 \mu \mathrm{m}$ particle atomized in nitrogen. Arrows show porosities. 


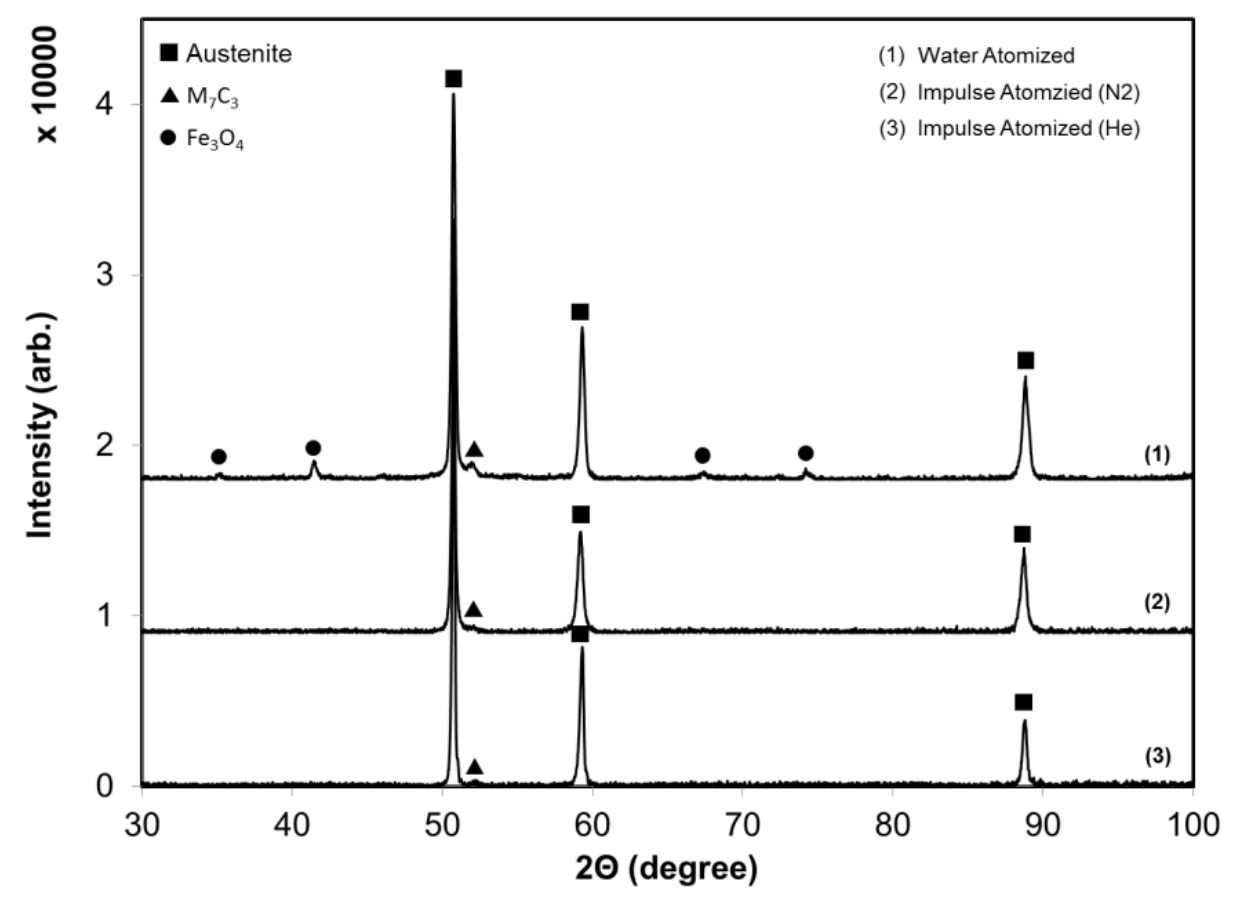

Figure 3. XRD patterns for $600-710 \mu \mathrm{m}$ particles produced via IA in helium and nitrogen as well as WA. 


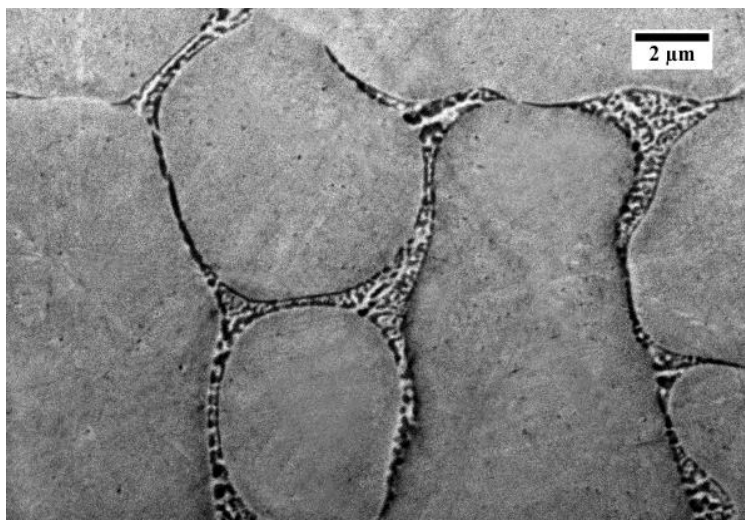

(a)

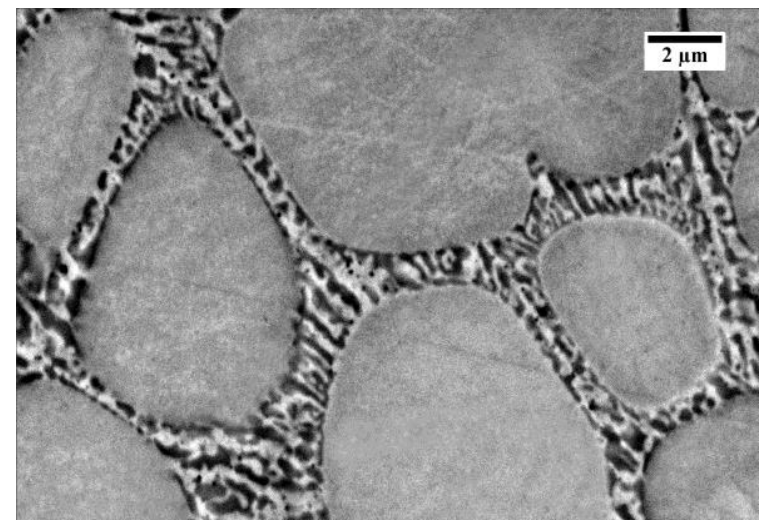

(b)

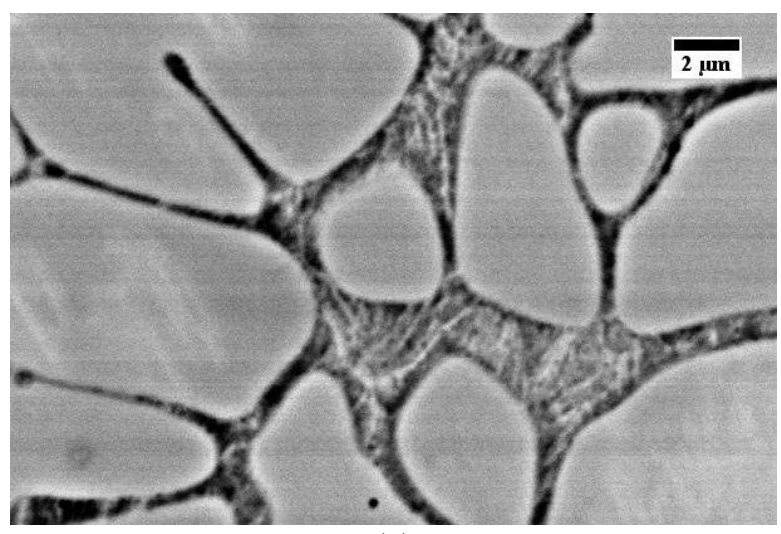

(c)

Figure 4. High-magnification SEM images of D2 tool steel: (a) $1200 \mu \mathrm{m}$ IA particle in helium, (b) $1200 \mu \mathrm{m}$ IA particle in nitrogen and (c) $655 \mu \mathrm{m}$ WA particle. 


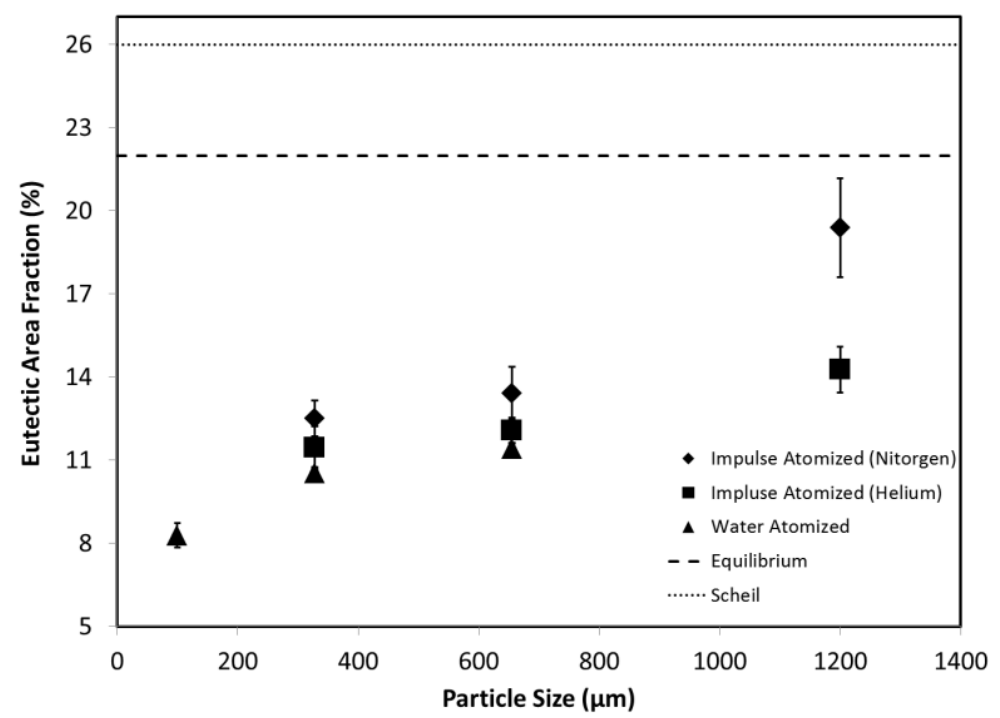

Figure 5. Eutectic area fraction as a function of particle size and cooling gas for IA and WA.

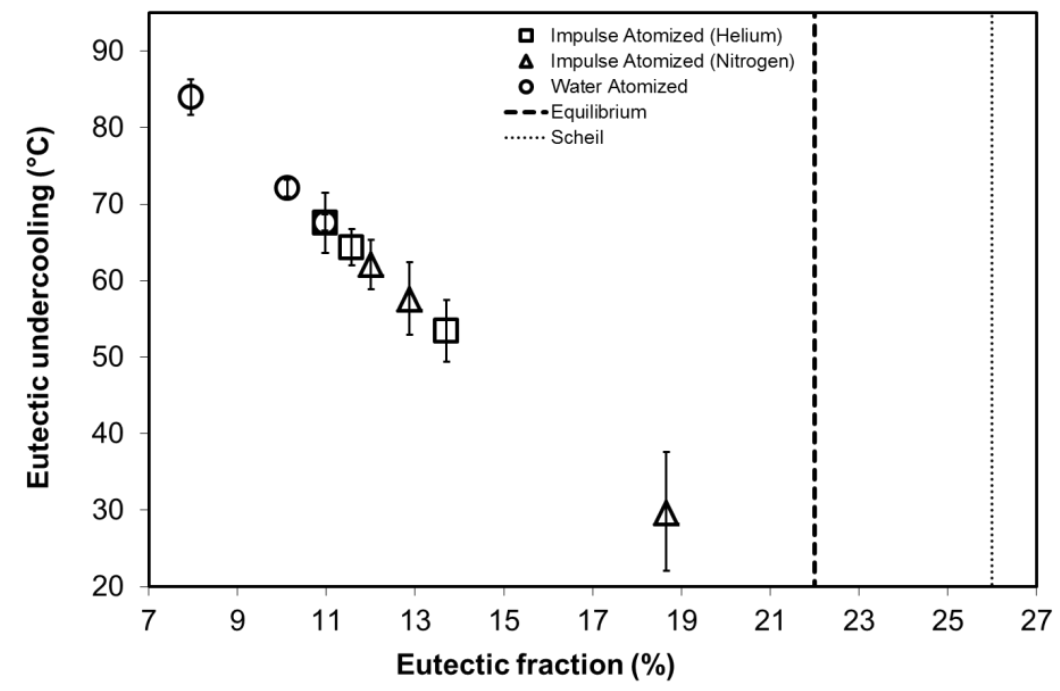

Figure 6. Effect of eutectic undercooling on the amount of eutectic in IA and WA D2 tool steel. 


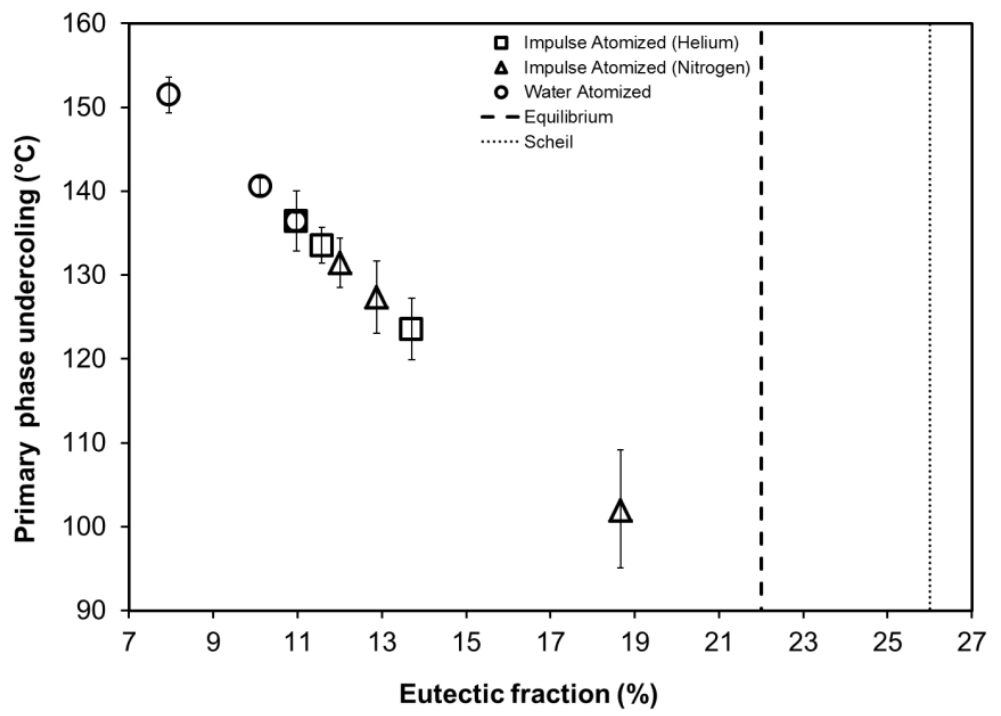

Figure 7. Effect of primary phase undercooling on the amount of eutectic in IA and WA D2 tool steel.

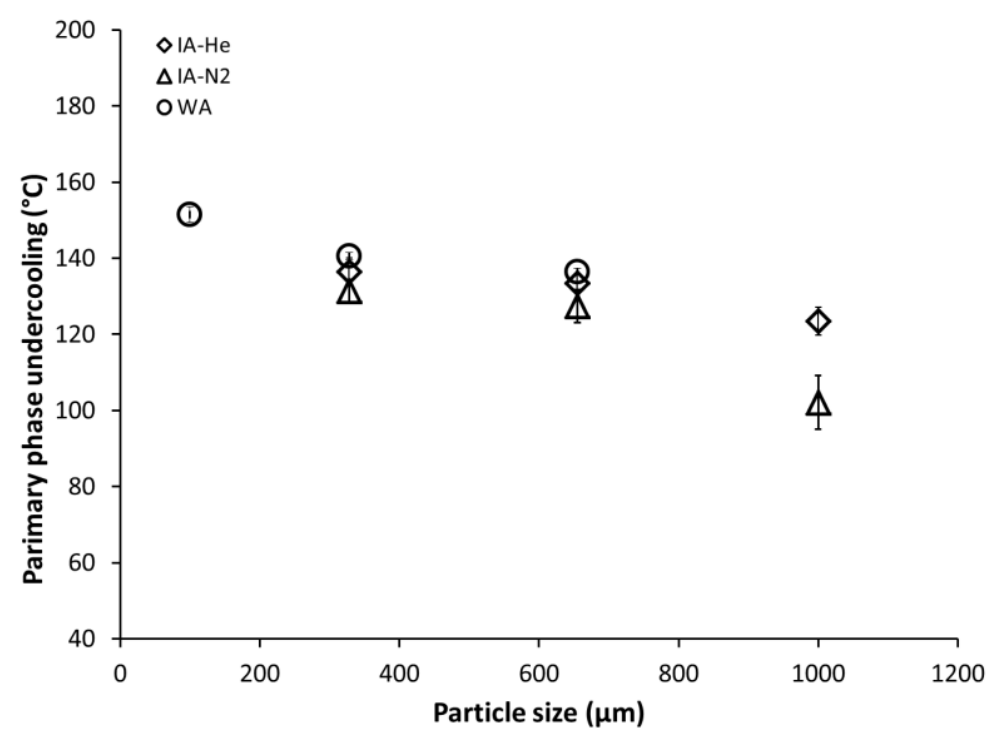

Figure 8. Effect of particle size on the primary phase undercooling. 


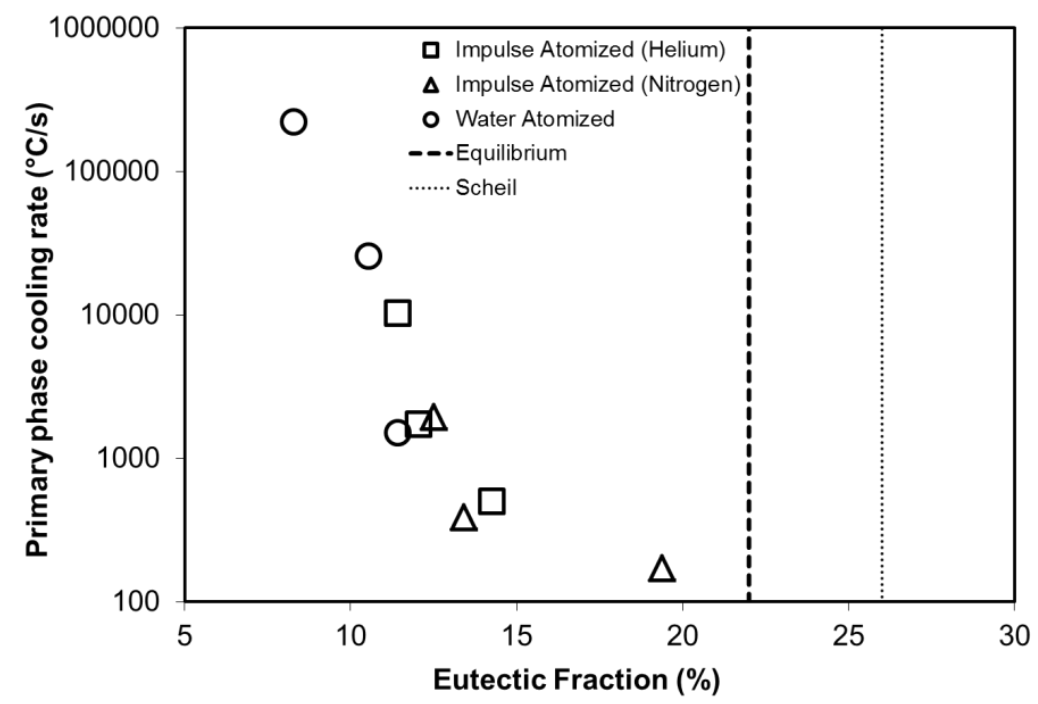

Figure 9. Effect of cooling rate of primary phase on the amount of eutectic in IA and WA D2 tool steel.

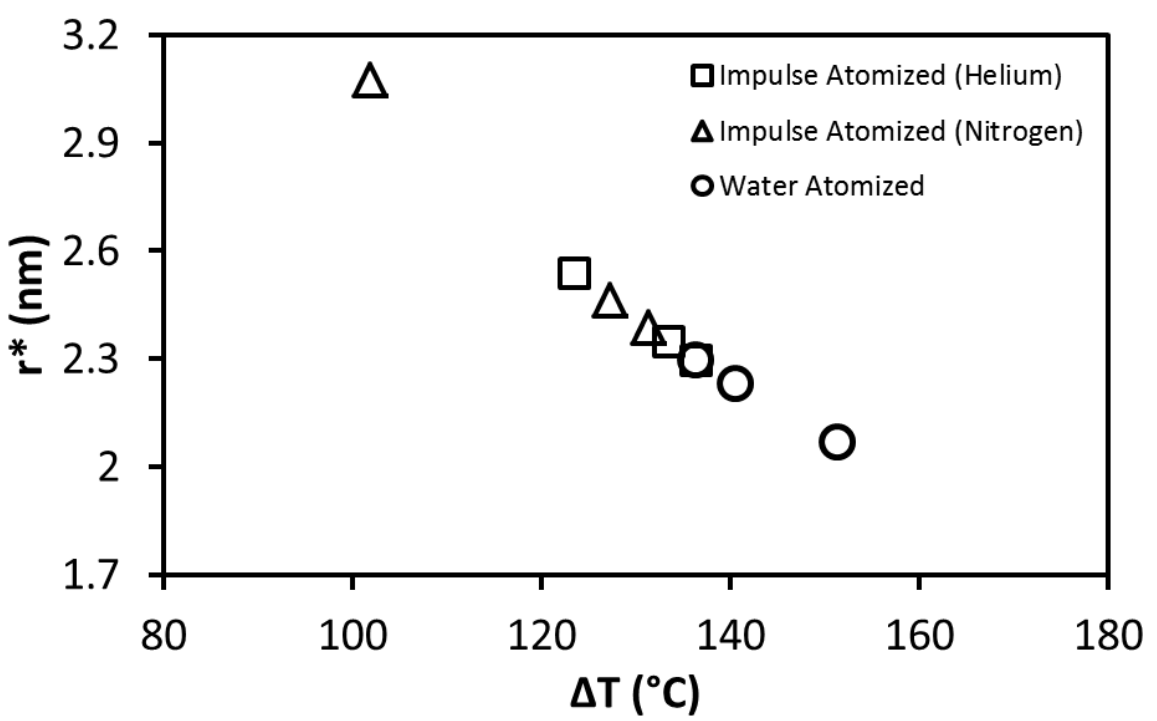

Figure 10. Critical nuclei radius as a function of primary phase undercooling. 


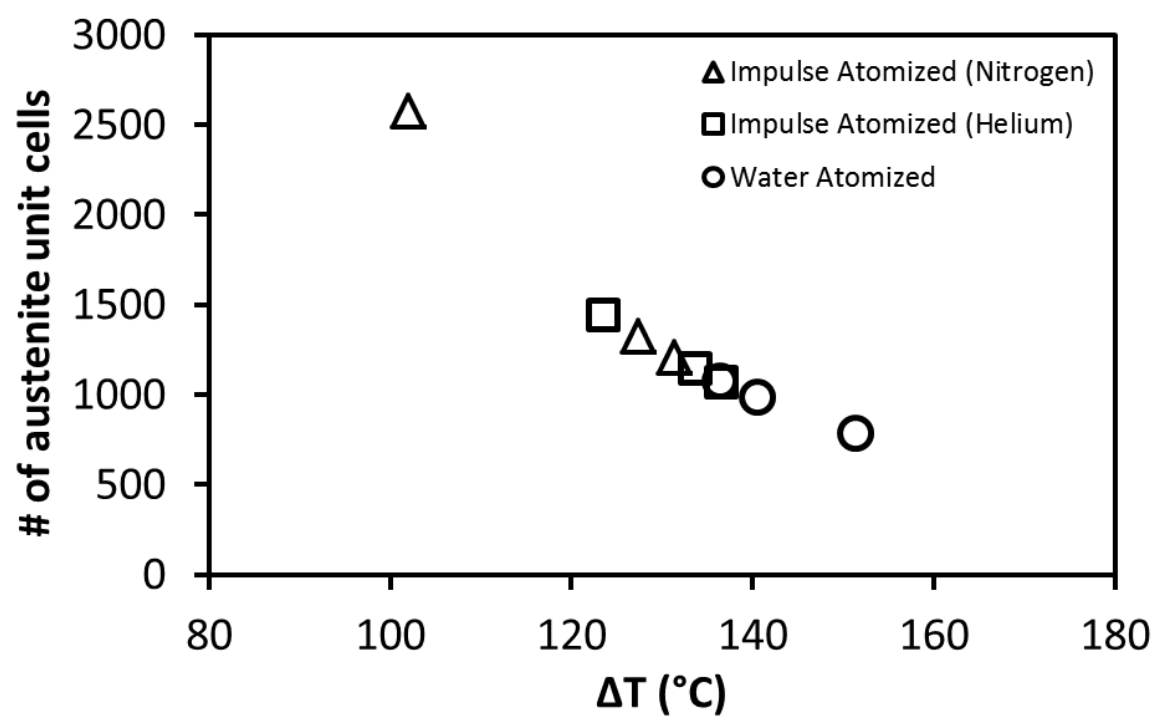

Figure 11. Number of austenite unit cells assuming homogeneous nucleation in the stable nucleus as a function of primary phase undercooling. 